\title{
Tempo presente e usos do passado: qual o lugar da epistemologia?
}

Present time and uses of the past: what is the place of epistemology?

VARELLA, Flávia; MOLLO, Helena Miranda; PEREIRA, Mateus Henrique de Faria; MATA, Sérgio da (orgs.). Tempo presente e usos do passado. Rio de Janeiro: FGV, 2012, 198 p.

\section{Douglas Attila Marcelino}

douglasattila@gmail.com

Professor adjunto

Universidade Federal de Minas Gerais

Av. Antônio Carlos, 6627 - Pampulha

31270-9001 - Belo Horizonte - MG

Brasil

Palavras-chave

Temporalidades; Memória; História do tempo presente.

Keywords

Temporalities; Memory; History of the present time. 
Reunindo textos dos trabalhos apresentados no IV Seminário Nacional de História da Historiografia, realizado em 2010 pelo Núcleo de Estudos de História da Historiografia e Modernidade (UFOP), o livro Tempo presente e usos do passado conjuga reflexões teóricas de importantes historiadores e intelectuais brasileiros sobre as especificidades relativas ao que se tem chamado "tempo presente". Apesar da diversidade de concepções, a coletânea apresenta grande coerência temática, aspecto nem sempre possível em seminários do mesmo tipo e que demonstra o acerto das escolhas feitas pelos organizadores. Justamente por isso, num primeiro plano, a obra pode servir para familiarizar o leitor com uma agenda de questões e problemáticas afins. Tal agenda se refere ao modo como temáticas que alcançaram enorme espaço no campo das reflexões teóricas nas últimas décadas adquirem singularidades quando confrontadas com interrogações acerca do passado recente ou das formas com que o mesmo tem sido predominantemente compreendido ou experimentado.

Assim, problemas amplos relativos aos usos da memória e às diferentes historicidades ganham relevância peculiar quando referidos ao trauma e aos passados sensíveis, ao lugar dos testemunhos, aos arquivos da repressão e às demandas sociais e desafios da judicialização que caracterizam a história recente, conforme abordado por Temístocles Cezar, Irene Cardoso, Paulo Knauss e Marieta de Moraes Ferreira. Reflexões sobre problemas conexos, embora centradas nas concepções de pensadores determinados, perpassam os estudos de Raquel Glezer e Olgária Chain Feres Matos sobre as obras de José Honório Rodrigues e Walter Benjamin, respectivamente. Particularmente significativa, por outro lado, é a pluralização dos "suportes" escolhidos para abordagem de problemas correlatos, indicativa de como os estudos sobre os usos do passado e as formas de experimentação do tempo e da memória se beneficiam de uma abertura ao campo da arte e da literatura: se o texto de Temístocles Cezar apresenta uma interessante análise do livro $W$ ou le souvenir d'enfance e da peça teatral $A$ morte e a donzela, na conferência de Durval Muniz de Albuquerque Júnior podemos ter contato com uma densa e imaginativa reflexão sobre as implicações de uma postura obsessiva em relação ao passado por meio da análise da presença do topos literário da cegueira advinda do excesso de claridade, tal como se poderia verificar na literatura pós-colonial de autores como José Saramago, Mia Couto e José Eduardo Agualusa (reflexão sugestiva do modo como a literatura, metaforicamente, pode dizer muito sobre as dificuldades de "inscrição" do passado geradas pelo conhecimento histórico quando da ausência de interrogações mais profundas sobre sua verdadeira utilidade para a vida). Outros textos, tratando diretamente de problemas teóricos referentes à sedução pelo tema da temporalidade, como o de Mateus Henrique Pereira e Sérgio da Mata, ou de questões nem sempre enfrentadas com mais acuidade nos debates sobre a "história do tempo presente", como na discussão de Carlos Fico sobre "perspectiva" e "distanciamento", completam a coletânea. Ela pode ser analisada considerando as convergências e divergências de algumas concepções apresentadas, bem como os esforços de relativização de interpretações estabelecidas por autores renomados e que repercutem de modo diferenciado nos debates feitos por historiadores brasileiros. 
Chama particular atenção, nesse caso, o texto introdutório de Mateus Pereira e Sérgio da Mata, pela problematização da presença quase obsessiva do tema da temporalidade a partir da última década do século passado. Tal presença, na crítica dos autores, seria fomentadora de leituras unilaterais sobre a onipotência do presente ou a crise do sentimento de aceleração típico da modernidade, tendo em vista as crescentes preocupações com a reconfiguração das formas com que se tencionam as sensações do passado, do presente e do futuro na experiência histórica de cada época determinada. Mais do que a crítica à amplitude da noção de "presentismo", de François Hartog, ou mesmo à interpretação sobre um esgotamento do "cronótopo moderno", tal como se poderia encontrar nos escritos de Hans Ulrich Gumbrecht, talvez um dos pontos mais relevantes do texto esteja no estímulo à reflexão sobre as formas com que os historiadores mais poderiam contribuir para esse tipo de debate, tendo em vista as peculiaridades atinentes ao modo com que temas correlatos tendem a ser tratados na disciplina. Retomarei o problema ao final, cabendo destacar outras dimensões da discussão que também não podem ser negligenciadas. Em última instância, elas apontam para o lugar das reflexões teóricas e epistemológicas dentro do ofício num duplo sentido: o primeiro, referido ao potencial explicativo que as mudanças no modo como os historiadores compreendem o conhecimento que produzem teriam para o entendimento das alterações na própria historiografia ao longo do tempo; o segundo refere-se ao papel da reflexão teórica, já que a crescente preocupação com a historicidade da disciplina não deveria escamotear o fato de que qualquer interrogação sobre a escrita da história carrega consigo algum teor normativo, mesmo quando sinceramente amparada numa preocupação com uma historicização radical de toda experiência. Talvez seja frutífero explorar tais questões a partir de diferentes leituras sobre aspectos pontuais presentes em textos da coletânea.

Um deles, por exemplo, refere-se ao surgimento da chamada "história do tempo presente" e ao crescimento do volume de estudos sobre o passado recente: seria tal mudança reflexo da ascensão de um "regime de historicidade" caracterizado pelo "presentismo", como indica Temístocles Cezar, repercutindo a leitura de François Hartog ${ }^{1}$ Uma alteração na forma de experimentação da temporalidade seria o fator fundamental que explicaria esse tipo de tendência na historiografia, ou seria preciso considerar outras variáveis, entre elas aquela referida ao próprio debate teórico produzido pelos historiadores envolvidos com o estudo do chamado "tempo presente"? Embora tratando de questão diversa, a reflexão de Carlos Fico sobre os motivos da interdição ao que chamaria de "história do tempo vivido", por exemplo, apontaria para variáveis distintas. Partindo do modo como o problema é interpretado nas teses de Reinhart Koselleck sobre as formas de experimentação do tempo histórico na modernidade, Carlos

\footnotetext{
${ }^{1}$ Segundo Temístocles, a recente obsessão pelo passado "não reflete uma ideia de história fundada no que teria de fato acontecido, mas em um regime de historicidade marcado pelo presente. Paradoxalmente, 0 passado que não quer ou não pode passar implica um presente que, igualmente, não passa, que continua, dura, resiste, nos cerca, e cujo significante historiográfico é a história do tempo presente" (VARELLA; MOLLO; PEREIRA; MATA 2012, p. 31-32).
} 
Fico pretendeu voltar-se para as próprias discussões dos historiadores e suas indagações políticas e epistemológicas acerca da verdadeira necessidade do estudo do passado recente. As questões formuladas pelos próprios historiadores, nesse caso, deveriam ser aspectos fundamentais de análise ou repercutem alterações mais profundas nas relações entre experiência e expectativa predominantemente estabelecidas em determinado presente histórico? Será que a desconfiança acerca do estatuto de cientificidade da história que acompanhou o abandono das crenças ingênuas na autotransparência do sujeito epistêmico, com suas ilusões acerca de uma autonomia da consciência e suas fincadas raízes na modernidade, tendeu a nos direcionar para interpretações da história da historiografia que desvalorizam o debate teórico produzido pelos próprios historiadores, superdimensionando processos que se desenvolvem de forma inconsciente numa mais larga duração histórica? Como considerar, por outro lado, essas distintas variáveis sem mergulhar numa retomada desavisada de uma confiança desmedida no debate epistemológico?

Sem dúvida, no caso da chamada "história do tempo presente", como argumentou Carlos Fico, as discussões que pretenderam defini-la como especialidade assumiram conotações essencialmente metodológicas, pouco tangenciando questões teóricas e epistemológicas mais profundas em favor de problemas referidos à periodização e nomenclatura. O mesmo se poderia dizer acerca das discussões conexas sobre um suposto retorno da história política nos anos 1970 e 1980, pautadas, muitas vezes de forma acrítica, nos instrumentais metodológicos e pressupostos holísticos que caracterizaram as primeiras gerações dos Annales. É desnecessário tratar do assunto, mas pode-se lembrar, por exemplo, das investidas de Jacques Julliard no uso da quantificação e da longa duração para o estudo dos fenômenos políticos em artigo conhecido da coleção Faire de I'histoire, ou mesmo das propostas de Jacques Le Goff de uma aproximação com a antropologia e a história das mentalidades por meio categoria "poder", compreendida como "última encarnação epistemológica do político", que permitiria acessar uma totalidade pressuposta no passado através, inclusive, da "dialética da duração" braudeliana. ${ }^{2}$ De modo geral, tais interpretações continuavam caracterizadas por pressupostos metodológicos e totalizantes cujo alcance talvez seja bastante limitado diante das reformulações em torno das teorias da ação e do significado que marcaram os anos 1980 (DOSSE 2003). Pelo menos no caso francês, portanto, os debates sobre a retomada do estudo histórico do passado recente e dos fenômenos políticos nem sempre foram acrescidos de interrogações epistemológicas mais fundamentais, o que nos impõe novamente a indagação sobre o verdadeiro significado das convicções teóricas dos historiadores na afirmação desse campo de pesquisas. Nesse caso, os diferentes encaminhamentos teóricos apresentados na coletânea servem para fomentar uma reflexão não apenas sobre a "história do tempo presente", mas também sobre a escolha de variáveis explicativas de maior ou

\footnotetext{
2 Os textos são de início dos anos 1970, embora traduzidos para o português nos anos 1980 (ver JULLIARD 1988; LE GOFF 1983). A conhecida batalha de Réne Rémond pelo reconhecimento de uma suposta autonomia do político nos anos 1980 não se pautava em concepções muitos distintas (RÉMOND 1996).
} 
menor alcance no estudo da história da historiografia, tendo em vista o caráter naturalmente incompleto de qualquer esforço de interpretação do passado.

Se a diferença na escolha de variáveis explicativas pode servir para pensar as especificidades do tratamento da história da historiografia, vale ressaltar que o livro também se compõe de convergências significativas, igualmente imprescindíveis ao debate acerca do estudo histórico do passado recente. Para não fugir aos exemplos examinados, podemos tomar um aspecto importante ressaltado nos textos de Temístocles Cezar e Carlos Fico: a singularidade do que se tem chamado "história do tempo presente" refere-se também ao modo peculiar com que o público leitor lida com temáticas que ainda ameaçam "a segurança psicológica de muitos" (para usar a feliz expressão que Temístocles Cezar reproduz do Posfácio de Ariel Dorfman à peça $A$ morte e a donzela). Temas considerados tabus, para os quais ainda funcionam várias interdições, objetos de recalques e obsessões: tal é o teor de parte substantiva do "material" com que se defrontam as análises dos historiadores sobre eventos pouco recuados no tempo. Esse, provavelmente, é um dos aspectos mais relevantes e nem sempre abordado de forma mais profunda quando se trata do estudo do passado recente.

Mark Salber Phillips, ao tratar do problema, formulou interrogações que tangenciam outra temática igualmente relevante, mas não priorizada nos textos da coletânea: quais os procedimentos experimentais, inclusive narrativos, de que os historiadores dispõem para causar um maior estranhamento em relação ao passado recente e, assim, produzir um "descentramento epistemológico" relevante em qualquer análise histórica que seja? ${ }^{3}$ Tal escolha permitiria pensar sobre até que ponto um maior distanciamento em relação ao objeto de análise está relacionado com a operação narrativa produzida pelo próprio historiador, e não apenas com características inerentes à natureza daquilo que chamamos de "realidade". Enfrentar o problema implicaria refletir como, enquanto unidades que fundamentam um discurso, os acontecimentos do passado recente ou mais recuado não possuem um estatuto de evidência ontológica que os faça plenamente independentes do modo como são estruturados nas explicações que construímos, seja por meio da natureza narrativa do ofício ou das elaborações teórico-metodológicas que potencializam o teor explicativo já presente em qualquer tipo de narrativa das experiências humanas passadas. ${ }^{4}$ Phillips, ao tratar de problema semelhante, destacou o uso de diferentes escalas de observação (no sentido atribuído por Giovanni Levi, de um recurso que é experimental, já que as escalas não existem como dados da "realidade") como um bom exemplo da adoção de uma perspectiva etnográfica geradora de certo estranhamento em relação ao passado (PHILLIPS 2004). Sabemos das experimentações da microhistória nesse sentido, mas parece que há ainda muito por fazer em direção à

\footnotetext{
${ }^{3}$ O texto de Phillips é mencionado por Carlos Fico, que indica também o problema da narrativa, embora não trate dele diretamente (PHILLIPS 2004).

${ }^{4}$ A bibliografia sobre o assunto é vasta, mas sigo aqui o sentido diferenciado que o debate parece ter tomado nos anos 1980 e 1990, como nas formulações de autores como Paul Ricoeur e Jörn Rüsen, por exemplo. O que chamo aqui de acontecimento, por outro lado, deve ser entendido no mesmo sentido dado por Fernando Catroga à noção de "fato histórico", ou seja, como construto epistemológico, formulado pelo historiador a partir da pressuposição ontológica do ocorrido. Segundo o próprio Catroga, "no plano epistêmico, um facto pode ser uma síntese que referencia milhares de acontecimentos" (CATROGA 2009, p. 114).
} 
adoção, por parte dos historiadores, de uma concepção mais atenta ao caráter experimental da narrativa histórica, que estimule a formulação e utilização de recursos que permitam lidar de modo mais sofisticado com os eventos passados.

Esse tipo de perspectiva permitiria a elaboração de uma análise histórica menos marcada pela urgência dos valores e demandas da conjuntura, distanciando-se do modelo de "história combatente" produzido por José Honório Rodrigues e analisado no texto de Raquel Glezer, por exemplo. Como apontou a autora, embora fizesse sentido num momento determinado, esse tipo de concepção tem sido desvalorizada, o que não significa, é claro, desconsiderar os condicionantes do presente que formatam qualquer abordagem histórica. Refletir sobre a dimensão experimental da narrativa histórica, por outro lado, corresponderia a aceitar que as discussões a respeito devem preocupar-se com o modo como um maior controle sobre as formas narrativas de produção de sentido acrescentam potencial cognitivo às interpretações historiadoras, que não deveriam ser entendidas apenas como prisioneiras de prefigurações inconscientes ou de estruturas profundas e incontroláveis da imaginação histórica. O próprio texto de Temístocles Cezar se aproxima da questão, ao ressaltar as proposições de Jörn Rüsen sobre as narrativas do Holocausto: as análises do historiador alemão sugerem um uso controlado dos mecanismos que tendem a tornar o discurso histórico um meio de "destraumatização", sugerindo um emprego consciente das fórmulas narrativas geradoras de sentido da memória histórica visando promover o que chamaria de uma "traumatização secundária" (RÜSEN 2009). Sem entrar em detalhes, o importante é a sugestão de que a própria narrativa histórica poderia servir para indicar os limites das formas de constituição histórica de sentido, tendo em vista a preocupação em não cair na tentação de conferir um estatuto mítico aos eventos traumáticos, presente em muitas análises que colocam o Holocausto no plano do indizível, tornando-o inacessível à cultura histórica.

Ressalte-se que, sob esse ponto de vista, o problema é analisado de um prisma que valoriza o potencial cognitivo do uso controlado das fórmulas narrativas de produção de sentido, afastando-se de outras perspectivas, que, conferindo autonomia quase completa aos operadores linguísticos, estimulam um "descentramento" do sujeito epistêmico que reproduz uma forma de abordagem estrutural que fez enorme sucesso no estudo de planos diversos da vida humana em boa parte do século passado. O assunto é conhecido e também as críticas aos supostos fundamentos anti-humanistas desse tipo de concepção, mas a revalorização do papel dos sujeitos históricos como agentes que não apenas reproduzem sentidos estruturalmente constituídos parece ter repercutido mais nos estudos diretamente voltados para a experiência humana passada do que naqueles centrados numa análise da própria produção historiográfica. Por isso, torna-se pertinente recolocar o problema: que papel devemos conferir às reflexões teóricas e epistemológicas dos próprios historiadores? Penso aqui, é claro, nas duas dimensões que atravessam a questão: qual o potencial explicativo das formulações presentes nos debates dos historiadores para a compreensão das alterações que caracterizam a própria escrita da história ao longo do tempo? Quais os ganhos 
efetivos da assunção de uma perspectiva que procure enfrentar os debates sobre os fundamentos do conhecimento histórico pautando-se no potencial cognitivo que poderia advir de um maior controle sobre as diversas dimensões do ofício que interferem no modo como o historiador dá sentido ao passado?

Ambas as questões, ao remeterem para o papel do sujeito historiador, repercutem o problema do próprio lugar da epistemologia histórica, mas também servem para indicar que as questões teóricas que envolvem as formas de explicação que fundamentam os estudos de história da historiografia não são de natureza diversa daquelas que atravessam qualquer outro tipo de estudo sobre a experiência humana passada. Não se trata, é claro, do retorno ingênuo a uma filosofia da consciência que resguardava ao sujeito um lugar pleno, como senhor do sentido, mas sim da indicação de que um "descentramento" total do debate epistemológico pode, na verdade, repercutir tendências já bastante desacreditadas no estudo de outros planos da vida humana. Trata-se também de pensar o próprio lugar da teoria numa disciplina que parece guardar muitas semelhanças com as características utilizadas por Clifford Geertz para definir a antropologia interpretativa, na qual voos mais longos de caráter teórico "tendem a se perder em sonhos lógicos, em embrutecimentos acadêmicos com simetria formal", já que "as formulações teóricas pairam tão baixo sobre as interpretações que governam que não fazem sentido ou têm interesse fora delas". Nesse tipo de saber, "qualquer generalidade" que o intérprete consegue alcançar surge mais "da delicadeza de suas distinções, não da ampliação de suas abstrações", o que aponta para a relevância do papel da evidência e da atenção às singularidades (GEERTZ 1989, p. 17). Ao contrário do que já se afirmou (LEVI 1992; BIERSACK 1992), essas formulações de Geertz não sugeriam que o trabalho antropológico prescindisse da teoria ou de reflexões congêneres, mas sim que há uma potencialidade teórico-filosófica intrínseca às explicações formuladas pela interpretação etnográfica.

Talvez essa vocação para um uso mais rigoroso das evidências, para uma maior preocupação com as sutilezas e as particularidades tenham sido alguns dos elementos que impulsionaram as críticas de Mateus Pereira e Sérgio da Mata à elaboração de diagnósticos mais amplos sobre a ascensão do "presentismo". Tal aspecto, entretanto, não parece inviabilizar um uso mais matizado da noção, tendo em vista sua importância como operador conceitual que, juntamente com outros disponíveis, pode fomentar análises frutíferas no campo da história da historiografia. Talvez Herder já suspeitasse da multiplicidade das experiências temporais quando afirmava que "cada coisa submetida à mudança leva em si a medida de seu tempo", que "não há duas coisas que levem a mesma medida de tempo" ou que "há no universo inumeráveis tempos em um tempo" (apud KOSELLECK 2004, p. 75-76). Ou ainda Burckhardt, para quem "ver o instante em corte faz pensar antes em um mosaico de peças em estados de desenvolvimento diferentes [...] que em um esquema irradiante conferindo significação a todas as peças" (citado em REVEL 2009, p. 105). Talvez esse tipo de reflexão sirva também para pensar o próprio lugar da história da historiografia nos dias de hoje: será que uma tendência à subvalorização das indagações teóricas dos próprios historiadores 
pode indicar a não percepção de que as explicações acerca das alterações no regime de escrita da história são de natureza semelhante àquelas formuladas para pensar qualquer outra experiência passada? As pesquisas históricas em geral, apesar do grau variável de sofisticação e consciência das escolhas entre diferentes variáveis explicativas, não tendem a formular teorias sobre a realidade passada empiricamente fundamentadas? O inegável fortalecimento da área de história da historiografia, representado, por exemplo, pela vitalidade da revista que publica esta resenha, torna-se extremamente positivo por recolocar em primeiro plano os debates epistemológicos, embora talvez não implique esquecer que o vetor teórico é intrínseco ao conhecimento histórico.

\section{Referências bibliográficas}

BIERSACK, Aletta. Saber local, história local: Geertz e além. In: HUNT, Lynn (org.). A Nova História Cultural. São Paulo: Martins Fontes, 1992, p. 97-130.

CATROGA, Fernando. Os passos do homem como restolho do tempo. Memória e fim do fim da história. Coimbra: Almedina, 2009.

DOSSE, François. O Império do sentido: a humanização das Ciências Humanas. São Paulo: EDUSC, 2003.

GEERTZ, Clifford. A interpretação das culturas. Rio de Janeiro: LTC, 1989.

JULLIARD, Jacques. A política. In: LE GOFF, J., NORA, P. (dir.) História: novas abordagens. Rio de janeiro: Francisco Alves, 1988, p. 180-196.

KOSELLECK, Reinhart. historia/Historia. Madrid: Minima Trotta, 2004.

LE GOFF, Jacques. A política será ainda a ossatura de história? In: . 0 maravilhoso e o cotidiano no ocidente medieval. Lisboa: Edições 70, 1983 , p. 215-229.

LEVI, Giovanni. Sobre a micro-história. In: BURKE, Peter (Org.). A escrita da história: novas perspectivas. São Paulo: UNESP, 1992, p. 133-161.

PHILLIPS, Mark Salber. History, Memory, and Historical Distance. In: SEIXAS, Peter (org.). Theorizing historical consciousness. Toronto: University of Toronto Press, 2004, p. 86-102.

RÉMOND, René (org). Por uma história política. Rio de Janeiro: UFRJ, 1996.

REVEL, Jacques. Proposições: ensaios de história e historiografia. Rio de Janeiro: EdUERJ, 2009.

RÜSEN, Jörn. Como dar sentido ao passado: questões relevantes de metahistória. História da Historiografia, n. 2, p. 163-209, mar. 2009. 